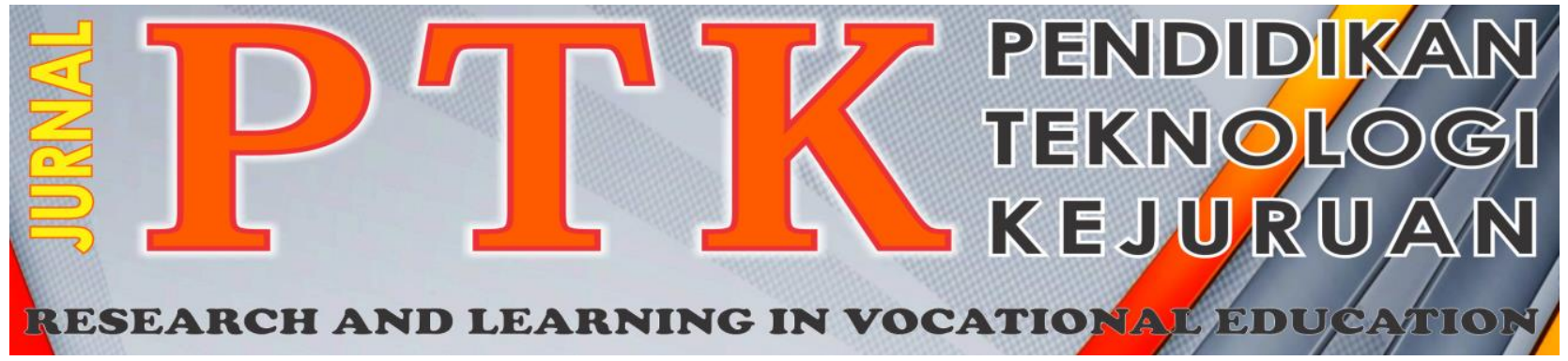

Vol. 1, No. 4, 2018

P-ISSN: 2621-3273

E-ISSN: 2621-1548

\title{
Sistem Informasi Layanan Akademik Pada Sekolah Menengah Kejuruan (SMK) Kosgoro 2 Payakumbuh Menggunakan Php Dan Mysql
}

\author{
Elmawati \\ SistemInformasi, Sekolah Tinggi Teknologi Industri Padang \\ "Corresponding author, e-mail: elmawati@ sttind.ac.id
}

\begin{abstract}
Abstrak - Perkembangan komputer yang semakin kompleks dapat mendorong setiap individu atau kelompok untuk menerapkannya dalam setiap aktifitas. Pengelolaan secara manual membutuhkan waktu lebih banyak. Salah satu Sekolah Menengah Kejuruan (SMK) Kosgoro 2 Payakumbuh, Sekolah ini belum memanfaatkan database sebagai media penyimpanan dari data-datanya. Sehingga proses pencarian data akan menghabiskan waktu yang cukup lama. Dengan menggunakan sebuah database, akan memudahkan pencarian data akademik seperti data guru, data penerimaan siswa baru, data sekolah dan data karyawan. Selain itu, pengarsipan data sekolah akan lebih rapi. Hasil penelitian menunjukkan bahwa sistem informasi akademik berbasis web yang dibangun dengan PHP dan MySQL dapat bekerja untuk membantu dalam proses penerimaan siswa baru. Program ini juga membantu dalam proses penyimpanan data-data siswa baru dan juga seluruh profil sekolah.
\end{abstract}

Kata kunci: Akademik,Web, PHP, MySQL

Abstract-The development of an increasingly complex computer world encourages each individual or group inevitably have to apply it in all activities. Management manually in addition to very much and will take more time. One of Vocational Secondary School (SMK) Kosgoro 2 Payakumbuh, this school has not utilized the database as a storage media of data-data. So the process of searching the data will take a long time. Using the database will facilitate the search for the desired academic data such as teacher data, new student admissions data, school data and employee data. In addition, school data archiving will be more neat.The results show that situs academic information built and PHP, MySQL can work to assist in the process of admission of new students. The program also helps in the process of storing new student data as well as the entire school profile.

Keywords: Academic, Web, PHP, MySQL

\section{Pendahuluan}

Sekolah Menengah Kejuruan (SMK) merupakan Institusi pendidikan yang tidak terlepas dari perkembangan teknologi informasi, yang dapat bermanfaat untuk meningkatkan mutu pendidikan di sekolah. Seperti memberikan kemudahan dan kepuasan kepada seluruh warga sekolah. Dan tidak hanya dalam kegiatan proses belajar mengajar, teknologi informasi sebaiknya juga dimanfaatkan sebagai media promosi sekolah kepada para calon siswa yang akan masuk ke sekolah tersebut, serta juga dapat memberikan layanan untuk pendaftaran bagi para calon siswa yang ingin mendaftar. Salah satu keuntungan dari penggunaan teknologi informasi pendaftaran supaya tidak memerlukan tempat yang luas untuk melakukan pendaftaran siswa baru. Pengarsipan data calon siswa baru pun menjadi lebih terstruktur dan tersimpan didalam sebuah database sehingga dapat menghemat tempat dan lebih efisien.

Dari beberapa persoalan yang telah dipaparkan pada latar belakang masalah di atas, penulis dapat mengidentifikasi masalah sebagai berikut :

1. Belum adanya sistem informasi untuk mendukung layanan akademik serta sarana untuk mempromosikan sekolah.

2. Dalam pengelolaan dan menyimpanan datadata Sekolah masih belum menggunakan database secara komputerisasi.

Berdasarkan identifikasi masalah di atas dan agar tidak terjadinya penyimpangan pembahasan, maka penulis membatasi masalah yang akan dibahas hanya sistem informasi akademik data penerimaan siswa baru, data guru, data karyawan, data sekolah dan informasi agenda kegiatan pada sekolah menengah kejuruan (SMK) Kosgoro 2 Payakumbuh. 
Berdasarkan uraian pada latar belakang diatas, maka rumusan masalah yang diambil yaitu:

1. Bagaimana membuat Sistem Informasi Akademik serta sarana promosi yang dapat menyimpan dan mengolah data di SMK ?

2. Bagaimana menerapkan Sistem Informasi Akademik secara komputerisasi untuk menyimpan dan mengelola data-data agar lebih terstruktur dan efesien secara online?

Berdasarkan rumusan masalah maka tujuan penelitian adalah

1. Membuat Sistem Informasi Akademik serta sarana promosi yang dapat menyimpan dan mengolah data di SMK.

2. Menerapkan Sistem Informasi Akademik untuk membantu dalam proses penyimpanan data-data sekolah agar lebih terstruktur dan efesien secara online.

3. laporan data siswa baru per tahun

\section{Metode}

Penelitian ini dilakukan untuk mengetahui gambaran pengembangan sistem informasi yang ada pada Sekolah Menengah Kejuruan (SMK) Kosgoro 2 Payakumbuh. Penulis menggunakan Jenis Penelitian terapan. Penelitian terapan yaitu penelitian yang dilakukan untuk mendapatkan informasi yang dapat digunakan untuk memecahkan masalah. Peneltian terapan dilakukan dengan tujuan untuk menerapkan, menguji, dan mengevaluasi masalah-masalah praktis sehingga dapat dimanfaatkan untuk kepentingan manusia, baik secara individual maupun kelompok.

Variabel penelitian adalah segala sesuatu yang akan menjadi pengamatan dalam penelitian.Sesuai dengan permasalahan yang diteliti maka variabel penelitian adalah data penerimaan siswa baru, data sekolah, data guru,data karyawandan data agenda kegiatan sekolah yang mana variabel penelitian tersebut diperoleh dari Sekolah Menengah Kejuruan (SMK) Kosgoro 2 Payakumbuh.

\section{HASIL DAN PEMBAHASAN}

\section{Analisa Dan Desain Sistem}

Analisis terhadap sistem lama merupakan tahap awal dalam pengembangan sistem itu sendiri, hal ini dilakukan agar perbandingan antara sistem yang baru dengan yang lama dapat dilihat dengan jelas. Hal ini juga dapat dijadikan tolak ukur sejauh mana perkembangan sistem tersebut berhasil dilakukan. Oleh karena itu penulis akan menjelaskan sedikit bagaimana sistem yang sedang berjalan di SMK Kosgoro 2 Payakumbuh.

Pada saat ini untuk kegiatan promosi sekolah masih dilakukan dengan menyebarkan lembaran brosur, untuk penerimaan siswa baru masih dilakukan secara manual yaitu dengan datang lansung ke sekolah dan pengisi lembaran formulir pendaftaran. Namun pada saat ini masyarakat telah banyak mengenal internet, dan kebanyakan orang lebih memanfaatkan internet untuk berbagai hal karna lebih mudah dan tidak menggunakan banyak waktu.

Hal ini perlu ditanggapi lebih serius oleh pihak sekolah SMK Kosgoro 2 Payakumbuh, karena sebagai sekolah yang sudah mulai dikenal di kalangan masyakat sudah seharusnya memiliki website sendiri terkait proses media promosi dan proses penerimaan siswa baru secara online.

Untuk penyimpanan data di SMK Kosgoro 2 Payakumbuh ini juga masih dilakukan secara manual seperti data guru data karyawan dan data sekolah, sehingga saat dibutuhkan masih membutuhkan waktu yang lama untuk mencari data tersebut.

Untuk mengatasi masalah yang dihadapi oleh sistem lama maka dapat dilakukan pembuatan sistem baru dengan melakukan hal sebagai berikut:

1. Pembuatan website promosi dan penerimaan siswa baru SMK Kosgoro 2 Payakumbuh dengan menggunakan aplikasi pendukung macromedia flash 8 .

2. Website tersebut tidak hanya untuk sarana promosi dan pendaftaran siswa baru saja, melainkan juga sebagai penyimpan data, seperti data sekolah data guru, dan data karyawan agar saat dibutuhkan tidak membutuhkan waktu lama untuk mencarinya

Desain system adalah merupakan tahap setelah analisa system dan tujuan dari desain system yaitu untuk pengambilan keputusan. Desain system bukan hanya mempercepat atau mengoptimalisasikan kegiatan operasi tetapi juga mencakup standarisasi dalam penghematan waktu dan biaya. Desain system ada dua tahap yaitu desain secara global dan desain secara terinci.

Perancangan sistem secara global ini dapatdilihat pada Use Case Diagram, Class Diagram dan Struktur Program.

Pada Use Case diagram yaitu menggambarkan bagaimana proses-proses yang dilakukan oleh aktor terhadap sebuah sistem. Untuk lebih jelas dapat dilihat pada gambar 1 . 


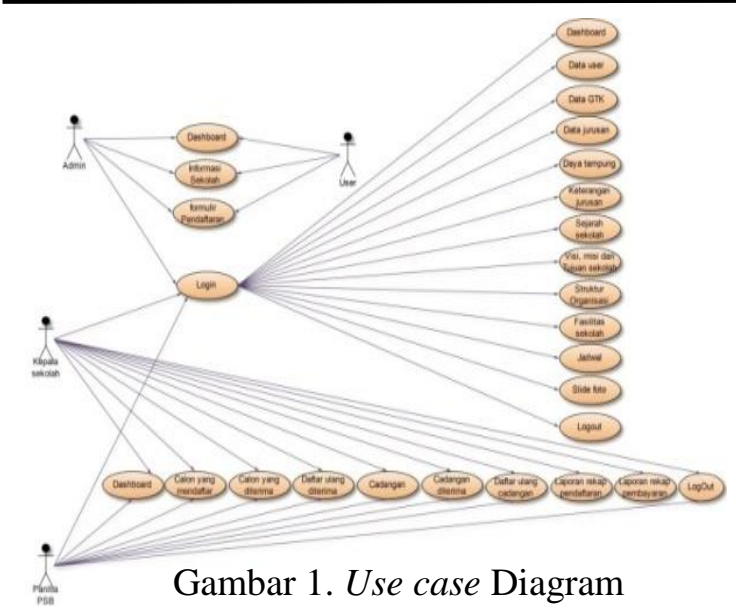

Class diagram merupakan gambaran hubungan antara tabel-tabel yang ada di dalam database. Dan masing-masing class mempunyai atribut serta metode dan fungsi sesuai dengan proses yang terjadi.

Berikut gambar 2. Class diagram darisistem akan dibangun :

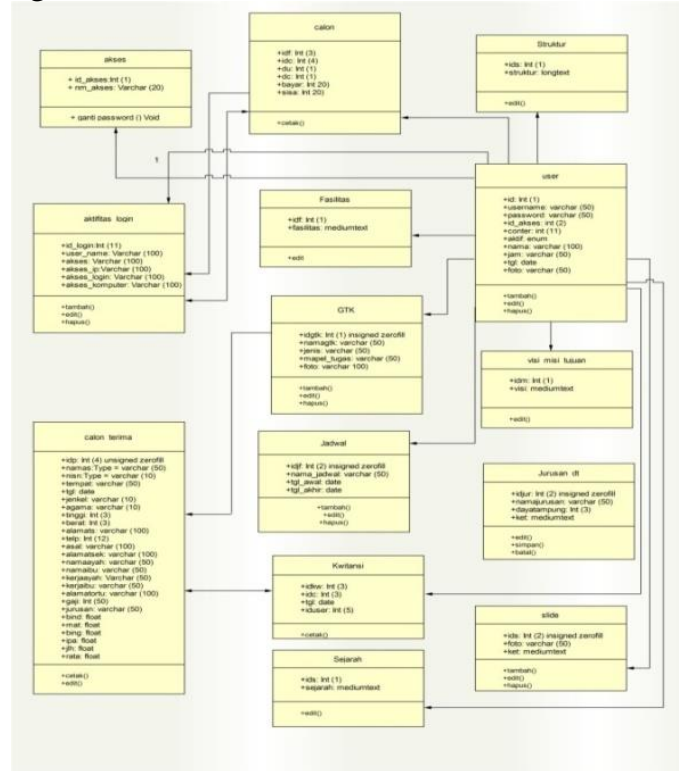

Gambar 2. Class Diagram

Sequence diagram digunakan untuk menjabarkan aktifitas yang ada pada use case kepada level yang lebih detail, berikut gambar sequence diagram:

1. Sequence diagram untuk admin

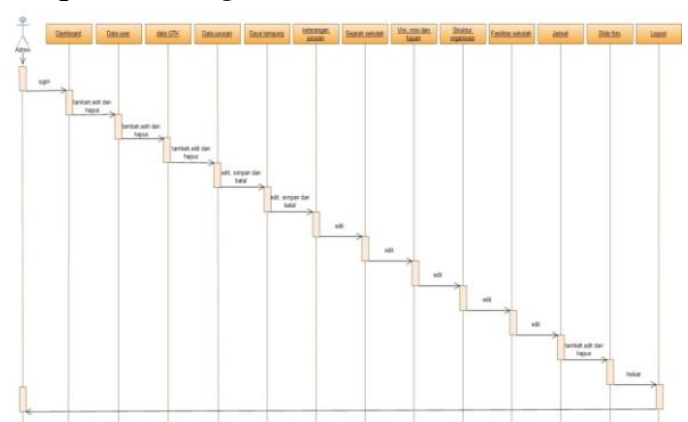

Gambar 3. Sequence diagram admin
Pada sequence diagram admin mengakses website untuk melakukan login ke dashboard untuk menginputkan data user, data GTK data jurusan, daya tampung, keterangan jurusan, sejarah sekolah, visi misi, struktur organisasi sekolah, fasilitas sekolah, jadwal penerimaan siswa baru, slide foto. Data-data yang telah ada dapat ditambah, edit, hapus data yang tersimpan kedalam database.

\section{Sequence diagram untuk User}

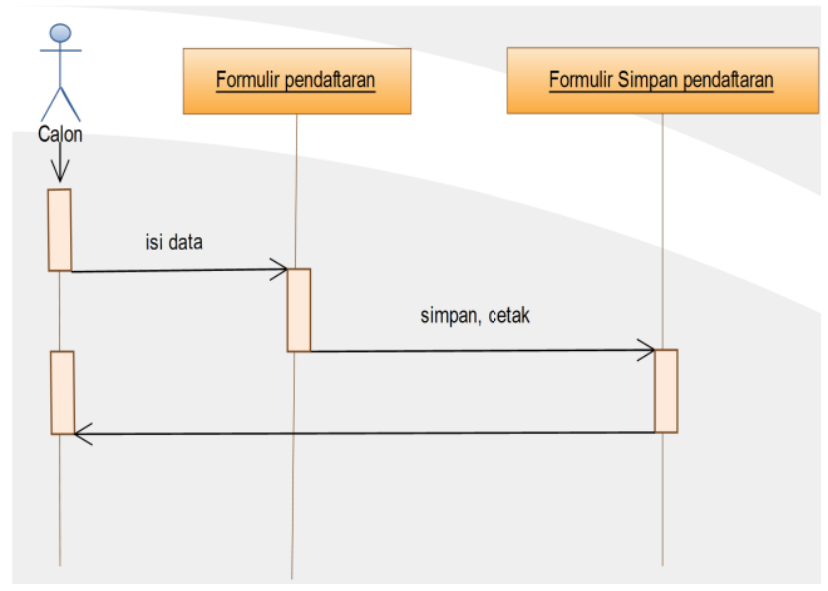

Gambar 4. Sequence diagram User

Pada sequence diagram user mengakses website untuk melakukan pendaftaran, dan formulir yang telah diisi bisa disimpan dan di cetak.

Activity diagram digunakan untuk memperlihatkan aliran dari suatu aktivitas ke aktivitas lainya dalam suatu sistem. Berikut gambar activity diagram.

1. Activity Diagram untuk Admin

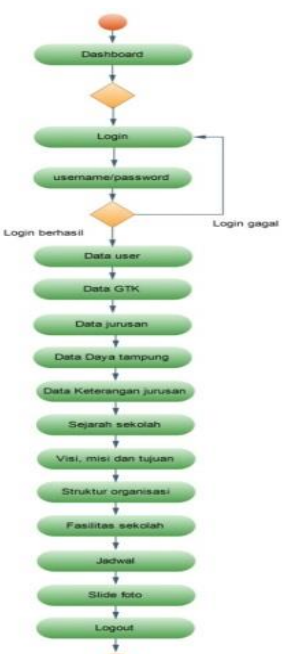

Gambar 5. Activity Diagram Admin

Aktivitas admin dimulai dengan mengakses web untuk melakukan login dengan menginputkan username dan password untuk dapat melihat dan mengedit menambah dan menghapus data-data yang ada. 


\section{Activity Diagram User}

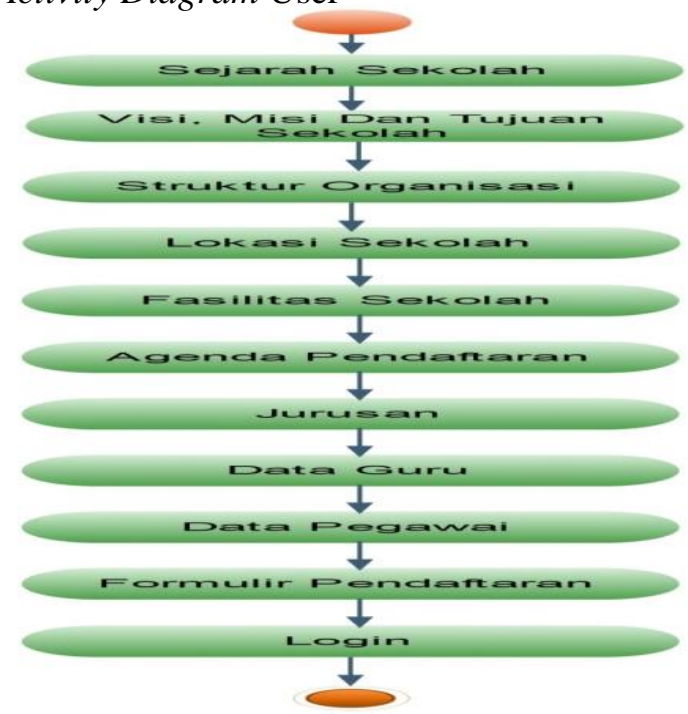

Gambar 6. Activity DiagramUser

Aktivitas siswa mendaftar dimulai dengan membuka web, setelah masuk menu Dashboard bisa klik menu formulir pendaftaran dan mengisi formulir, setelah mengisi formulir klik from simpan pendaftaran agar pendaftaran berhasil.

\section{Implementasi Sistem}

Implementasi sistem adalah suatu prosedur yang dilakukan pada tahap sistem dalam dokumen yang disetujui dan menguji kemudian menginstal dan menggunakan program yang dibuat.

Didalam implementasi sistem ada beberapa tahap yang harus dilakukanadalah:

1. Menerapkan rencana implementasi

2. Melakukan kegiatan implementasi dan tindak lanjut implementasi.

Untukmengimplementasikan sistem yangakandirancang, maka diperlukan sebuah alat berupa komputer, yang mana untuk mengoperasikan komputer itu sendiri terdapattigakomponen pendukung seperti hardware, software, dan brainware.

Untuk merancang dan mengimplementasikan sistem yang dirancang diperlukan sebuah alat berupa komputer sebagai media yang dapat membantu dalam pengaplikasikannya. Pada komputer terdapat tiga komponen penting yang seperti hardware, software dan brainware.

Menu utama adalah menu awal yang ditampilkan ketika pertama kali kita mengakses website.

Pada tampilan menu utama ini menampilkan menu Dashboard, sejarah sekolah, visi, misi sekolah, struktur organisasi, lokasi sekolah, fasilitas sekolah, agenda pendaftaran, jurusan, data guru, data pegawai, formulir pendaftaran dan menu login.

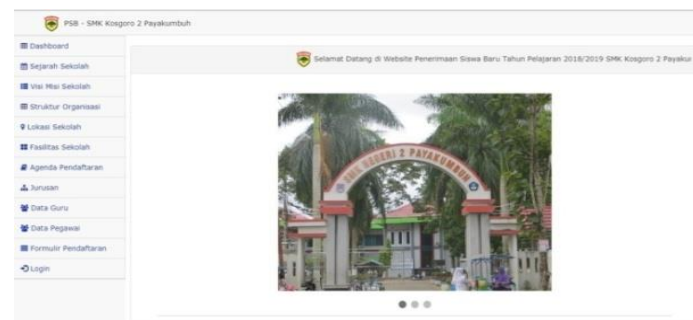

Gambar 7. Tampilan Dashboard

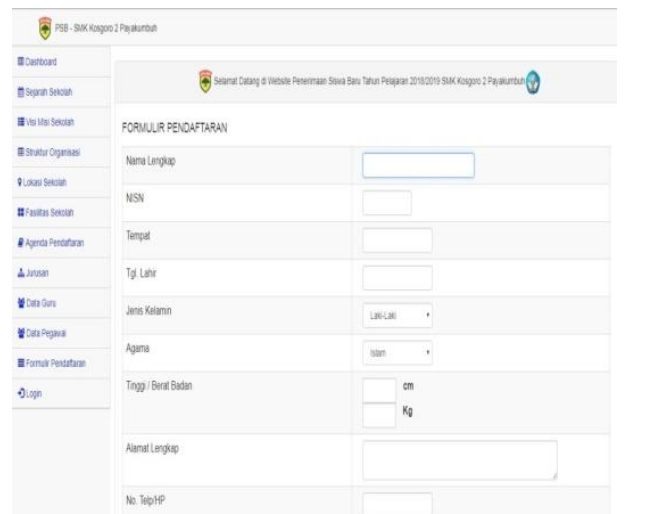

Gambar 8. Tampilan Menu Formulir Pendaftaran

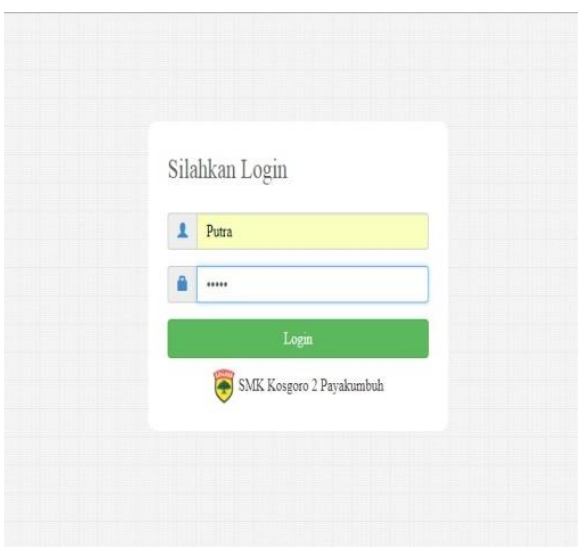

Gambar 9. Tampilan Menu Login

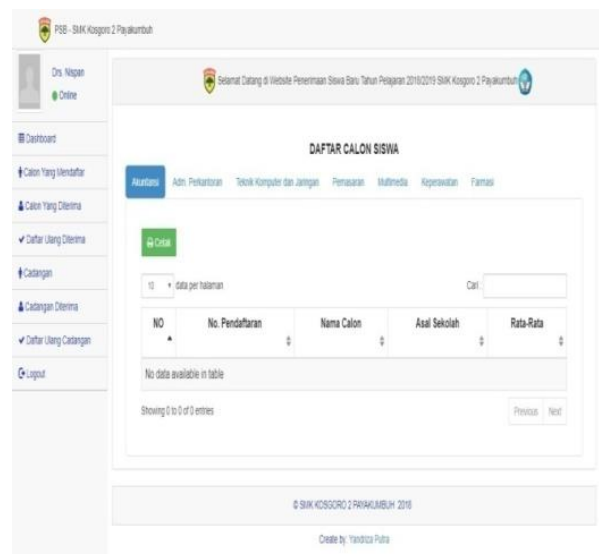

Gambar 10. Tampilan Menu Calon Sisiwa yang Mendaftar 


\section{KESIMPULAN}

Sistem informasi Akademik pada Sekolah Menengah Kejuruan (SMK) Kosgoro 2 Payakumbuh yang awalnya masih manual dijadikan berbasis web memiliki beberapa keuntungan yang penulis rangkum dalam kesimpulan sebagai berikut:

1. Dapat diakses dari mana saja dan kapan saja melalui jaringaninternet sehingga lebih membantu terutama dalam sarana promosi dan pendaftaran online.

2. Dengan diterapkannya aplikasi ini dapat memberikan kemudahan kepada Calon siswa baru yang ingin mendaftar tanpa harus datang kesekolah terlebih dahulu.

\section{DAfTAR PUSTAKa}

[1] Firdaus, PHP dan MySQL dengan mackromedia Dreamweaver 8 . Jakarta.2007

[2] Ladjamuddin, Bin Al-bahra. Dasar Pemograman Web Dan Desain Sistem Informasi: Yogyakarta.2005

[3] Y. Arbi and E. R. Aidha, "SIMULATION OF MERCURY TRANSPORT FROM GOLD MINING ACTIVITIES IN PELAWAN RIVER , SAROLANGUN," 2017, vol. 4, pp. 567-571.

[4] Y. Arbi, R. Siregar, and Tri Padmi Damanhuri, "KAJIAN PENCEMARAN AIR TANAH OLEH LINDI DI SEKITAR AIR DINGIN KOTA PADANG," SAINS DAN Teknol. STTIND $P A D A N G$, vol. 18, no. 1, 2018.

[5] Nugroho, Bunafit. Membuat Sistem Informasi Penjualan Berbasis Web Dengan PHP dan MySQL. Yogyakarta: Gave media. 2004.

[6] Satzinger, Jackson, Burd. Pengertian Analisa dan Perancangan sistem. 2012

[7] Pratama, Antonius N. W. 2010. CodeIgniter: Cara Mudah Membangun Aplikasi PHP. Jakarta : Media Kita.

[8] Elmawati and S. Angga, "Perancangan Aplikasi Pemesanan Menu Makanan Dan Minuman Pada Cafe Living Room Bukittinggi," J. Sains dan Teknol., vol. 17, no. 2, pp. 1-7, 2017

[9] Elmawati, Nofriadiman, and H. Yulita, "PERANCANGAN SISTEM INFORMASI PEMODELAN LABOR PRAKTIKUM PROSES MANUFAKTUR," J. Sains dan Teknol., vol. 18, no. 2, 2018. 